\title{
Simulation of Convergent Divergent Rocket Nozzle using CFD Analysis
}

\author{
K.P.S.Surya Narayana ${ }^{1}$, K.Sadhashiva Reddy ${ }^{2}$ \\ ${ }^{1,2}$ (B. Tech, Department of Mechanical Engineering, BVRIT, Narsapur, Telangana, India)
}

\begin{abstract}
A rocket nozzle is a mechanical device which is designed to control the rate of flow, speed, direction and pressure of stream that exhaust through it.There are various types of rocket nozzles which are used depending upon the mission of the rocket. This paper contains analysis over a convergent divergent rocket nozzle which is performed by varying the number of divisions in mesh. Also the various contours of nozzle like Cell Equiangle skew, Cell Reynolds number, Pressure,Velocity, Mach Number, and above are calculated at each type of mesh using CFD analysis software ANSYS Fluent.
\end{abstract}

Keywords: ANSYS Fluent, Convergent, Cell Reynolds Number, Mesh, Molecular Prandtl Number.

\section{Introduction}

A nozzle is a device which is used to give the direction to the gases coming out of the combustion chamber. Nozzle is a tube which has a capacity to convert the thermo-chemical energy generated in the combustion chamber into kinetic energy. The nozzle converts the low velocity, high pressure, high temperature gas in the combustion chamber into high velocity gas of lower pressure and low temperature. A convergentdivergent nozzle is used if the nozzle pressure ratio is high. High performance engines in supersonic aircrafts generally incorporate some form of a convergent-divergent nozzle. Our analysis is carried using softwares like Ansys Workbench for designing of the nozzle and Fluent 15.0 for analyzing the flows in the nozzle. In the present days there is a huge development in Aerospace Engineering for in various prospects. Extensive research is being carried out in the fields like civil and defense prospects. The virtualization is one of the major developments in the field of research, which has revolutionized Aerospace engineering, along with all other branches. The computational techniques are being used widely for getting better results, which are close to experimental techniques. The flow through a convergent-divergent nozzle is one of the benchmark problems used for modelling the compressible flow through computational fluid dynamics. In this paper CFD analysis of a convergent divergent rocket nozzle is done by varying the number of divisions in Mesh and obtaining results for various parameters like pressure, temperature, properties, wall fluxes, Mesh, velocity and adaption.

\section{Literature}

A convergent-divergent nozzle is designed for attaining speeds that are greater than speed of sound. The design of this nozzle is obtained from the area-velocity relation $(\mathrm{dA} / \mathrm{dV})=-(\mathrm{A} / \mathrm{V})\left(1-\mathrm{M}^{\wedge} 2\right)$ where $\mathrm{M}$ is the Mach number (which means the ratio of local speed of flow to the local speed of sound) A is area and V is velocity.

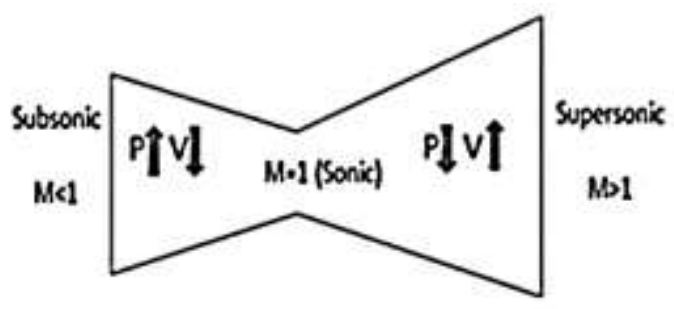

From the above fig we can observe that

a. The decrease in Area results in the increase of pressure and decrease in velicity as seen in the above figure at the entry of the nozzle.

b. The increase in area results in increasing the velocity at the exit of the nozzle by decreasing the pressure.

Also we can find out that

i. $\quad \mathrm{M}<1$ results in subsonic speeds.

ii. $\mathrm{M}=1$ results in sonic speeds.

iii. $\mathrm{M}>1$ results in supersonic speeds.

One important point is that to attain supersonic speeds there is a need to maintain favorable pressure ratios across the nozzle. 


\subsection{Modelling}

\section{Methodology and implementation}

The Geometry of the nozzle was created using ANSYS WORKBENCH 15.0.
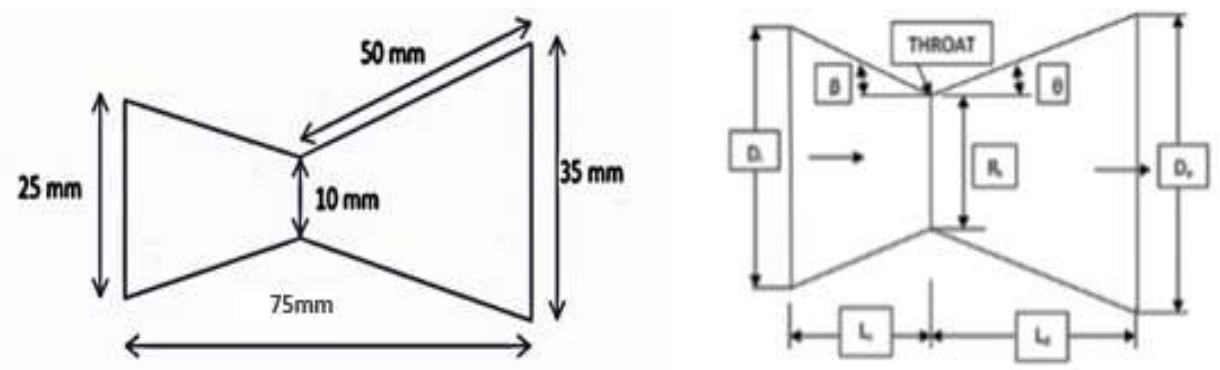

\section{Design Parameters}

\begin{tabular}{|l|l|}
\hline Inlet diameter & $25 \mathrm{~mm}$ \\
\hline Throat diameter & $10 \mathrm{~mm}$ \\
\hline Exit diameter & $35 \mathrm{~mm}$ \\
\hline Pressure & $3 \mathrm{bar}$ \\
\hline Ideal gas Viscosity & Sutherland \\
\hline
\end{tabular}

\subsection{Meshing In ANSYS Workbench}

After the modelling is completed the meshing is to be done. The module used to perform meshing is Fluid Flow (Fluent). The meshing method used here is Automatic Method and the mesh type is selected as All Quad. The overning equations used in mesh are as follows: It is assumed that there is a unique, single valued relationship between the generalized co-ordinates and the physical co-ordinates which can be expressed as $\eta=\eta(x, y) \xi=\xi(x, y)$

this also implies that, $x=x((\xi, \eta) y=y(\xi, \eta)$

The functional coordinates are determined by the mesh generation process. Given these functional relationships, the governing equations are transformed into corresponding equations containing partial derivatives with respect to the parametric space.For example

$$
\begin{aligned}
& \frac{\partial T}{\partial x}=\frac{\partial T}{\partial \xi} \frac{\partial \xi}{\partial x}+\frac{\delta T}{\delta \eta} \frac{\delta \eta}{\delta x} \\
& \frac{\partial T}{\partial y}=\frac{\partial T}{\partial \xi} \frac{\partial \xi}{\partial y}+\frac{\delta T}{\delta \eta} \frac{\delta \eta}{\delta y}
\end{aligned}
$$

The inverse transformation can be written as follows:

$$
\begin{aligned}
& \frac{\partial T}{\partial \xi}=\frac{\partial T}{\partial x} \frac{\partial x}{\partial \xi}+\frac{\delta T}{\delta y} \frac{\delta y}{\delta \xi} \\
& \frac{\partial T}{\partial \eta}=\frac{\partial T}{\partial x} \frac{\partial x}{\partial \eta}+\frac{\delta T}{\delta y} \frac{\delta y}{\delta \eta}
\end{aligned}
$$

The Poisson Equation that is solved is of the form as in the following equations :

$$
\begin{aligned}
& \frac{\partial^{2} \xi}{\partial x^{2}}+\frac{\partial^{2} \xi}{\partial y^{2}}=\mathrm{P}(\xi, \eta) \\
& \frac{\partial^{2} \eta}{\partial x^{2}}+\frac{\partial^{2} \eta}{\partial y^{2}}=\mathrm{Q}(\xi, \eta)
\end{aligned}
$$

Where $\mathrm{P}$ and $\mathrm{Q}$ are predefined functions that are used to control grid clustering. Here in this project Meshing plays a main role, since we are obtaining results by varying the Number of divisions in mesh. The number of divisions are varied at the vertical surfaces (inlet and exit) and the inclined surfaces (walls). 


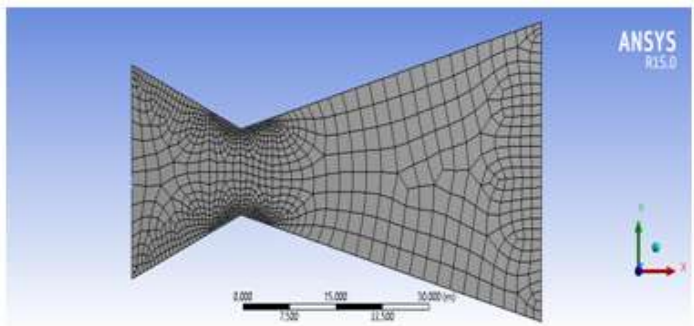

Fig. 1

The mesh obtained initially will be unstructured mesh (fig.1) and this cannot be used to obtain accurate results. Since the edges are prismatic the mesh can be converted into structured meshing by using Mapped Face Meshing. The analysis is done for five types of meshes which are obtained by varying the number of divisions in mesh. The variation of the number of divisions is done on the inlet, exit and on the walls of the nozzle. The following is the nomenclature that is followed to mention the Number of divisions. N1-Number of divisions on the Inlet and exit of the nozzle $\mathrm{N} 2-\mathrm{Number}$ of divisions on the inclined walls of the nozzle.

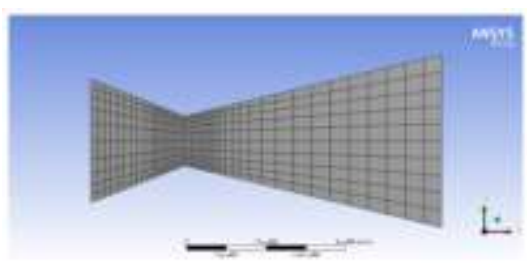

Fig.2(a) $\mathrm{N} 1=10, \mathrm{~N} 2=10$

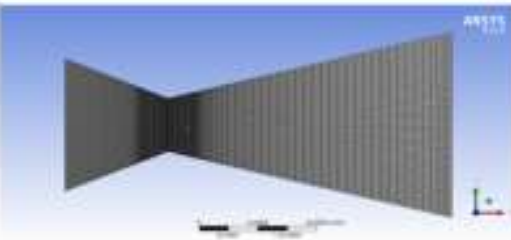

Fig.2(c) $\mathrm{N} 1-50, \mathrm{N2}-30$

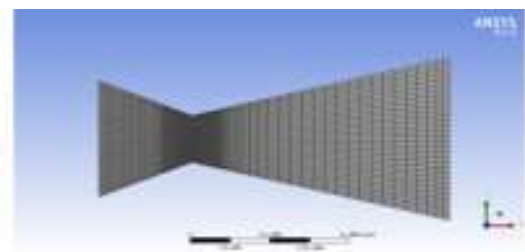

Fig.2(b) $\mathrm{N} 1=30, \mathrm{~N} 2 m 20$

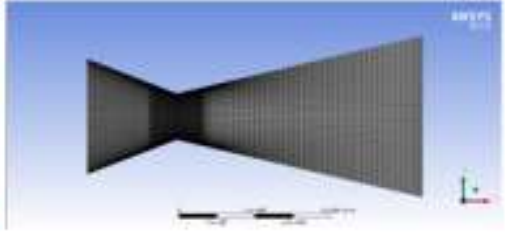

Fig. 2(d) $\mathrm{N} 1-70, \mathrm{N2}=90$

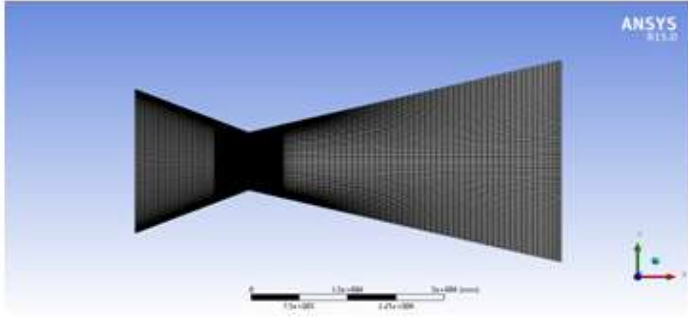

Fig. 2 (e) $\mathrm{N} 1=90, \mathrm{~N} 2=50$

The following table provides the information about the type of mesh associated with a particular type of number of mesh divisions over a surface.

\begin{tabular}{|c|c|c|c|c|}
\hline Mesh 1 & Mesh 2 & Mesh 3 & Mesh 4 & Mesh 5 \\
\hline $\mathrm{N} 1=10$ & $\mathrm{~N} 1=30$ & $\mathrm{~N} 1=50$ & $\mathrm{~N} 1=70$ & $\mathrm{~N} 1=90$ \\
$\mathrm{~N} 2=10$ & $\mathrm{~N} 2=20$ & $\mathrm{~N} 2=30$ & $\mathrm{~N} 2=90$ & $\mathrm{~N} 2=50$ \\
\hline
\end{tabular}

From the above we can observe that the number of divisions at N1 are being varied by 20, whereas at N2 the variation is 10 for each mesh. 


\subsection{Boundary Conditions}

1. Mass flow inlet

2. Outlet

3. Walls

Specification of the boundary zones has to be done in WORKBENCH only, as there is no possibility to specify the boundary zones in FLUENT. Therefore proper care has to be taken while defining the boundary conditions in WORKBENCH. With all the zones defined properly the mesh is exported to the solver. The solver used in this problem is ANSYS FLUENT. The exported mesh file is read in Fluent for solving the problem.

\subsection{Solving}

FLUENT analysis is carried out on nozzle at different meshing conditions.

\section{Analysis Procedure}

The same procedure is followed for all the 5 types of mesh and the results are validated.

\begin{tabular}{|c|c|}
\hline PROCEDURE & DETAILS \\
\hline $\begin{array}{l}\text { Problem Setup } \\
\text { General-Solver }\end{array}$ & $\begin{array}{l}\text { Type: Density based } \\
\text { Velocity : Absolute } \\
\text { Time: Steady } \\
\text { 2D space: Planar }\end{array}$ \\
\hline Models & $\begin{array}{l}\text { Energy :On } \\
\text { Viscous: Laminar }\end{array}$ \\
\hline Materials & $\begin{array}{l}\text { Fluid :Air } \\
\text { Density: Ideal Gas } \\
\text { Viscosity: Sutherland }\end{array}$ \\
\hline Boundary conditions & $\begin{array}{l}\text { Inlet : Pressure Inlet } \\
\text { Gauge Total Pressure (pa): } 3 \mathrm{e} 5 \\
\text { Outlet : Pressure Out let } \\
\text { Gauge Pressure(pa): } 0\end{array}$ \\
\hline Reference Values & $\begin{array}{l}\text { Compute from : Inlet } \\
\text { Reference Zone : Solid Surface body }\end{array}$ \\
\hline Monitors & $\begin{array}{l}\text { Create-walls -cd } 1 \\
\text { Select Print to console and plot. }\end{array}$ \\
\hline Initialization & $\begin{array}{ll}\text { Standard Initialization } \\
\text { Compute from Inlet. }\end{array}$ \\
\hline Solution & $\begin{array}{l}\text { Solution Controls - Courant Number }=5 \text {. } \\
\text { Run Calculation: Enter the Number of iterations, } \\
\text { Click calculation. }\end{array}$ \\
\hline
\end{tabular}

\subsection{Convergence History}

\section{Results And Discussion}

The following graphs present the convergence history of the nozzle at different types of meshes.

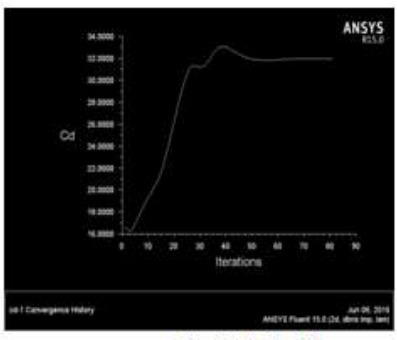

Fig,3(a) Mesh 1

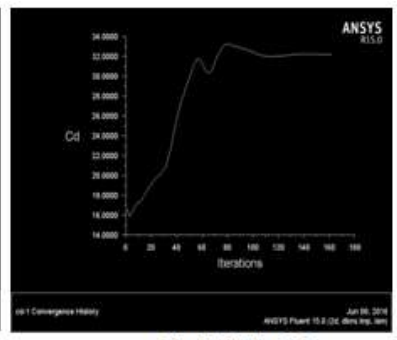

Fig.3(b) Mesh 2

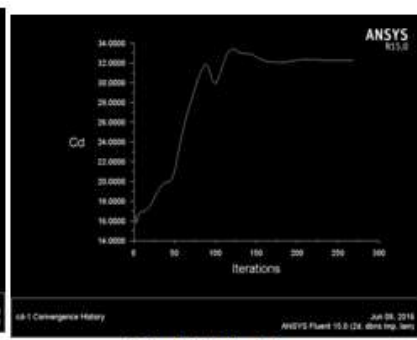

Fig. 3(c) Mesh 3

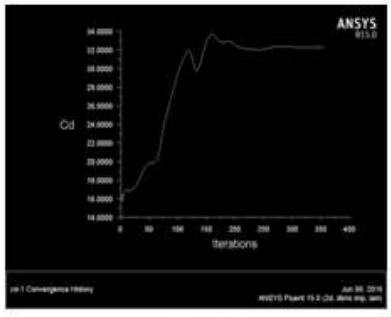

Fig. 3(d) Mesh 4

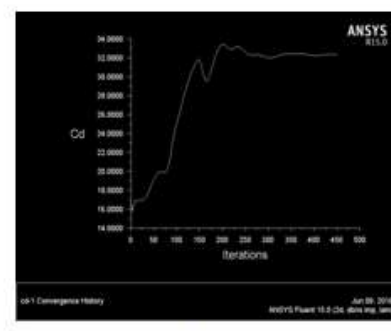

Fig.3 (e) Mesh 5 
The solution is converged after 83 iterations for mesh1, 165 iterations for mesh2, 268 iterations for mesh 3, 342 iterations for mesh 4, and 440 iterations for mesh 5.

\subsection{Static Pressure}

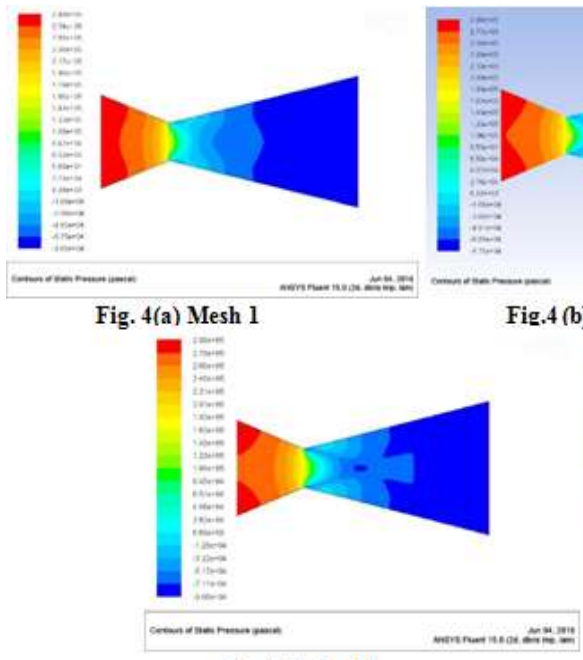

Fig .4(d) Mesh4
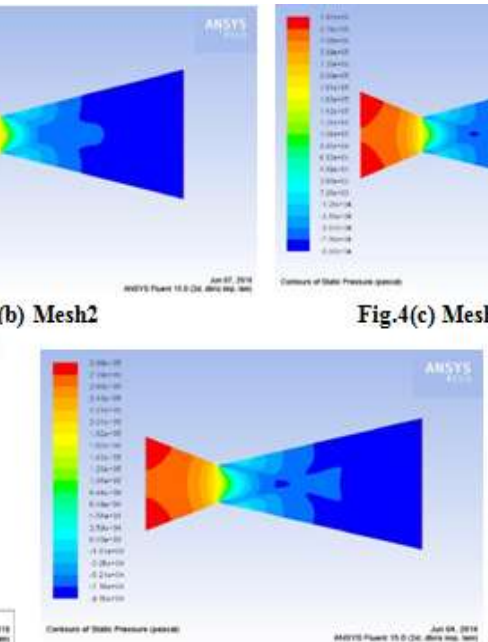

Fig. 4(e) Mesh 5

The results obtained for the static pressure at each type of mesh are as follows.

\begin{tabular}{|c|c|c|}
\hline Mesh & Min value (Pa) & Max value (Pa) \\
\hline 1 & -86476.05 & 292786.7 \\
\hline 2 & -87471.49 & 295932.2 \\
\hline 3 & -89273.85 & 296949.1 \\
\hline 4 & -90591.82 & 298549.4 \\
\hline 5 & -91049.52 & 298767.8 \\
\hline
\end{tabular}

The maximum value of the static pressure increases from Mesh 1 to Mesh 5 gradually. The maximum value at mesh1 is 292786.7 and the value is increased at mesh 5 as 298767.8

\subsection{Dynamic Pressure}

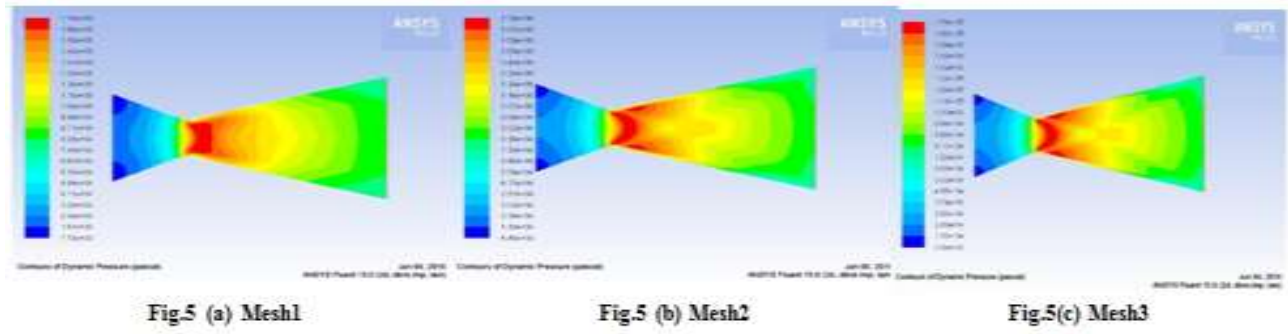

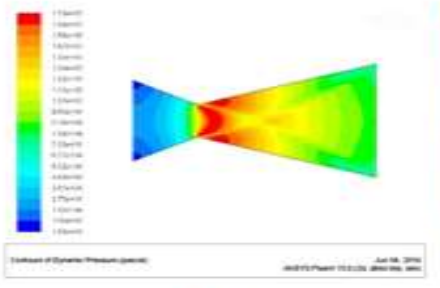

Fig. 5(d) Mesh4

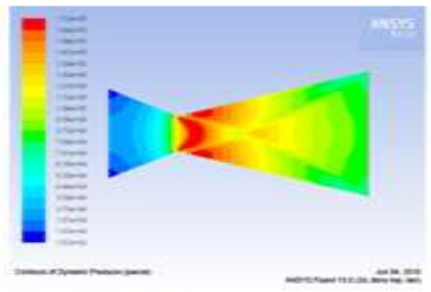

Fig.5 (e) Mesh5

The results obtained for the dynamic pressure over each type of mesh are as follows:

\begin{tabular}{|c|c|c|}
\hline Mesh & Min value (Pa) & Max Value (Pa) \\
\hline 1 & 7786.104 & 174392.5 \\
\hline 2 & 4451.948 & 175928.7 \\
\hline 3 & 3340.72 & 176164.5 \\
\hline 4 & 1845.276 & 172981.3 \\
\hline 5 & 1572.161 & 172838.4 \\
\hline
\end{tabular}


As we observe the minimum value of the dynamic pressure decreases gradually on the increase in the number of mesh divisions.

\subsection{Mach Number}
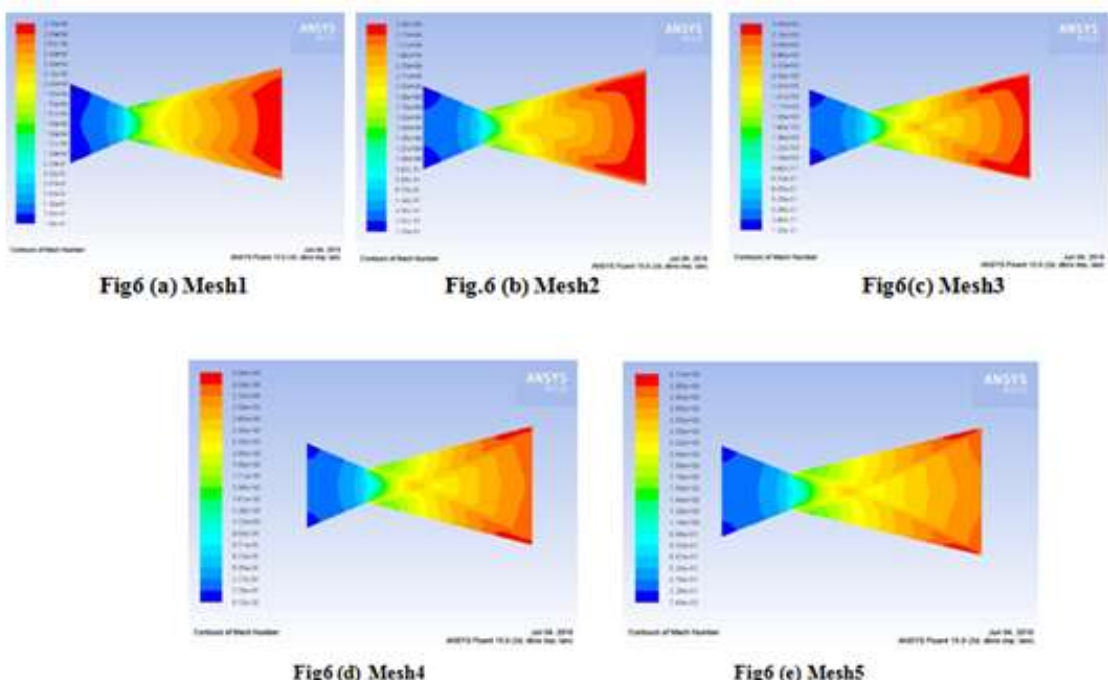

The obtained results for the Mach number on the variation of mesh size are as follows:

\begin{tabular}{|c|c|c|}
\hline Mesh & Min & Max \\
\hline 1 & 0.1677308 & 2.784976 \\
\hline 2 & 0.1264253 & 2.844711 \\
\hline 3 & 0.1094085 & 2.878834 \\
\hline 4 & 0.08119585 & 3.038563 \\
\hline 5 & 0.074926 & 3.105635 \\
\hline
\end{tabular}

The Mach number on increase in the number of mesh divisions shows a considerable increase in its value from 2.784976 to 3.105635 as shown in the above table.

\subsection{Molecular Prandtl Number}

The following are the results obtained for the molecular prandtl number:

\begin{tabular}{|c|c|c|}
\hline Mesh & Min & Max \\
\hline 1 & 0.7441759 & 0.7441761 \\
\hline 2 & 0.7441759 & 0.7441762 \\
\hline 3 & 0.7441759 & 0.7441762 \\
\hline 4 & 0.7441759 & 0.7441762 \\
\hline 5 & 0.7441759 & 0.7441762 \\
\hline
\end{tabular}

The contours of the Molecular Prandtl Number are shown below.

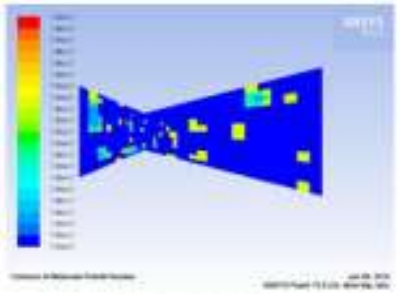

Fig, 7 (a) Meshl

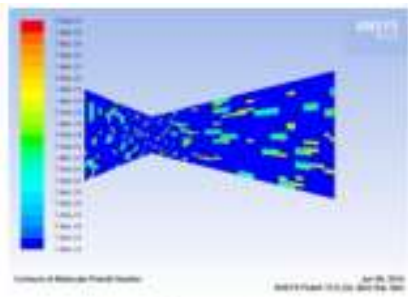

Fig.7 (b) Mesh2

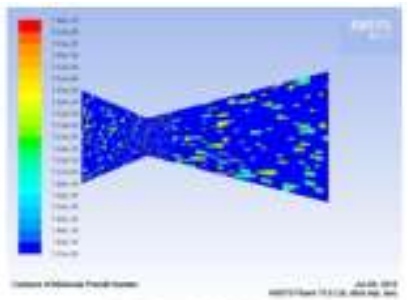

Fig.7(c) Mesh3

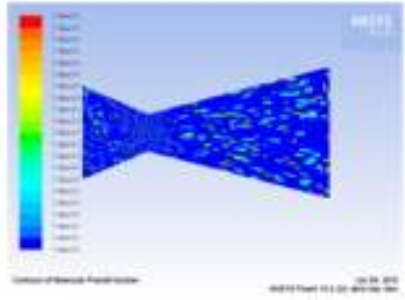

Fig. 7(d) Mesh4

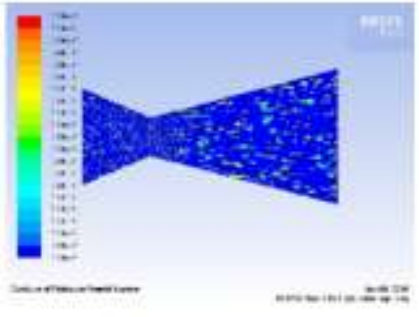

Fig.7 (e) Mesh5 


\subsection{Cell Reynolds Number}

the contours of Cell Reynolds Number are presented above. The following table elucidates the results obtained at

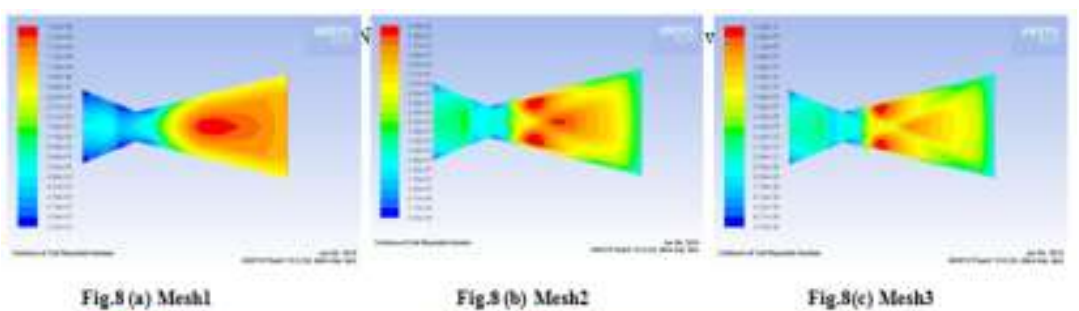

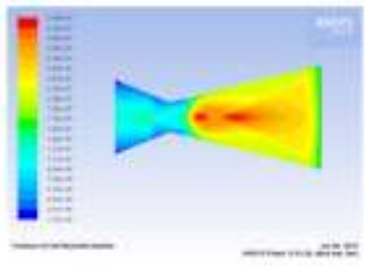

Fig.8 (d) Methe

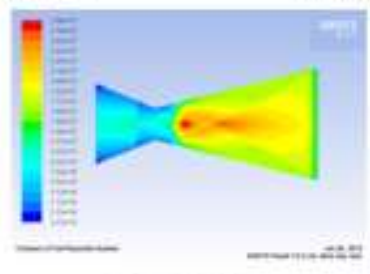

Fig.8 (e) Meshs

The contours of Cell Reynolds Number are presented above. The results obtained are elucidated below in the following table.

\begin{tabular}{|c|c|c|}
\hline Mesh & Min & Max \\
\hline 1 & $2.072836 \mathrm{e}+07$ & $1.323412 \mathrm{e}+08$ \\
\hline 2 & 6348036 & $3.400297 \mathrm{e}+07$ \\
\hline 3 & 3764984 & $2.389734 \mathrm{e}+07$ \\
\hline 4 & 1346941 & $3.38988 \mathrm{e}+07$ \\
\hline 5 & 922478.5 & $2.892826 \mathrm{e}+07$ \\
\hline
\end{tabular}

\subsection{Cell Equi angle Skew}

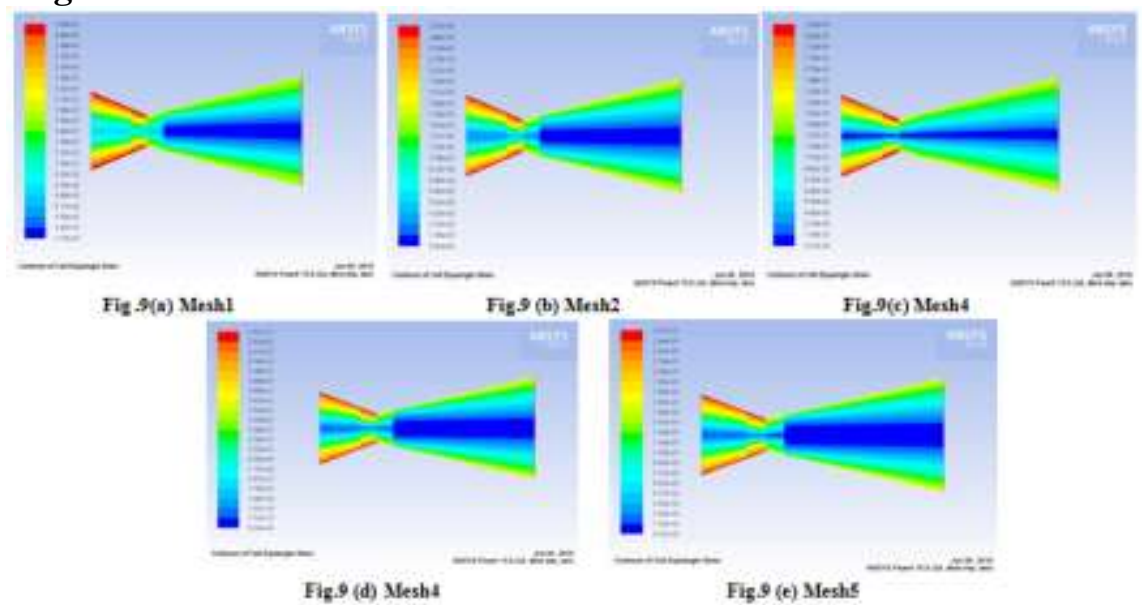

The following are the results obtained for the cell equi angle skew after solving in Fluent.

\begin{tabular}{|c|c|c|}
\hline Mesh & Min & Max \\
\hline 1 & 0.02246387 & 0.2575587 \\
\hline 2 & 0.004999726 & 0.2570593 \\
\hline 3 & 0.006369548 & 0.2571762 \\
\hline 4 & 0.0005017999 & 0.2571143 \\
\hline 5 & $5.518553 \mathrm{e}-05$ & 0.2571229 \\
\hline
\end{tabular}

\subsection{Orthogonal Quality}

The results obtained for the orthogonal quality are as follows,

\begin{tabular}{|c|c|c|}
\hline Mesh & Min & Max \\
\hline 1 & 0.9205856 & 0.9993722 \\
\hline 2 & 0.9178777 & 0.999963 \\
\hline 3 & 0.9197189 & 0.9999467 \\
\hline 4 & 0.9126614 & 0.9999996 \\
\hline 5 & 0.8950424 & 1 \\
\hline
\end{tabular}


As we observe the max orthogonal quality remains almost the same on the variation of the mesh divisions. The contours of the orthogonal quality are presented below,
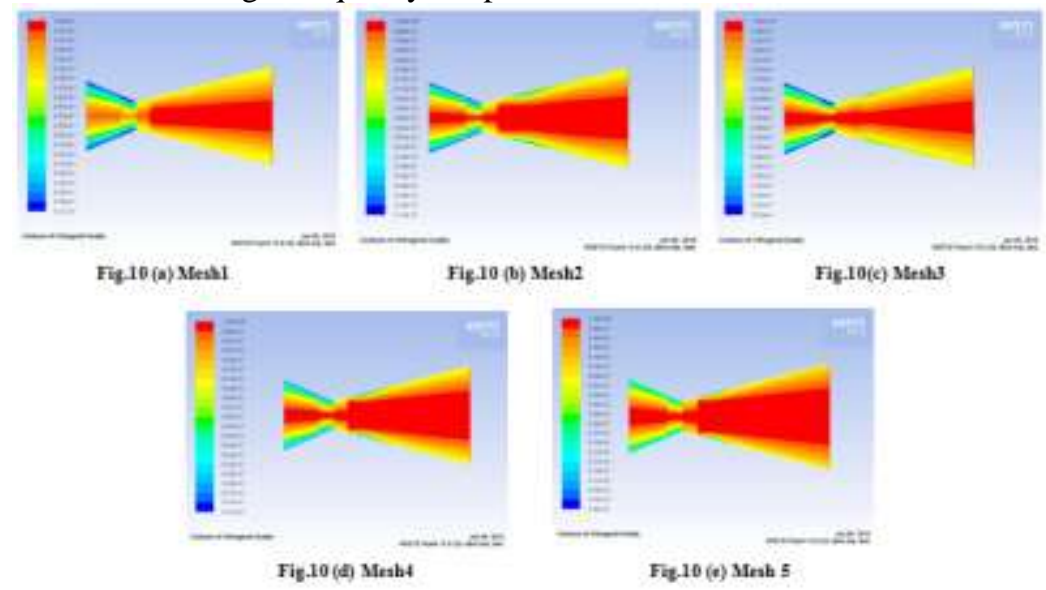

\section{Conclusion}

A nozzle model was developed to determine the pressure, Mach number, cell equi angle skew, cell Reynolds number, molecular prandtl number and orthogonal quality in it.Various steps of the model were validated with good accordance with the experimental data and numerical results found in the literature. The contours of the above mentioned parameters are found after analyzing the model successfully in the solver. Also the minimum and maximum values of all the parameters at all the five types of mesh are tabulated.

\section{Acknowledgements}

We would like to thank Mr. Prabhakaran Sir for his support and help in using the Ansys software. We would also like to thank Dr.V. Murali Krishna Sir for constant support and motivation throughout the project work. We would also like to thank Mr.P Vinay Kumar Sir.We would also like to thank Dr. Ch. Venketeshwarlu Sir for providing the right platform. Finally, we would like to thank Almighty.

\section{References}

[1]. P. Parthiban, M. Robert Sagayadoss, T. Ambikapathi, Design And Analysis Of Rocket Engine Nozzle by using CFD and Optimization of Nozzle parameters, International Journal of Engineering Research, Vol.3., Issue.5., 2015 (Sept.-Oct.).

[2]. Bogdan-Alexandru Belega, Trung Duc Nguyen, Analysis of Flow in Convergent-divergent rocket engine nozzle using Computational Fluid Dynamics, International Conference Of Scientific Paper Afases 2015 Brasov, 28-30 May 2015.

[3]. Balaji Krushna.P, P. SrinivasaRao, B. Balakrishna , Analysis Of Dual Bell Rocket Nozzle Using Computational Fluid Dynamics, IJRET: International Journal of Research in Engineering and Technology eISSN: 2319-1163 | pISSN: 2321-7308.

[4]. Dumonov, G., Ponomaryov, N.B. and Voinov, A.L.,(1997)“'Dual-Bell Nozzles for Rocket Engines of Launch Vehicle Upper Stages and Orbital Transfer Vehicles,' AIAA Paper 97-3089, 33rd AIAA/ASME/SAE/ASEE Joint Propulsion Conference \& Exhibit, USA, Luglio.

[5]. Abdulnaser Sayma, Computational Fluid Dynamics.

[6]. Hagemann, G., Immich, H. and Preuss, A,(3-6 December 2002,)"Advanced Nozzle Concepts for Future Rocket EngineApplications', 4th International Conference on Launcher Technology, Liege, Belgium.

[7]. K.M.Pandey and S.K.Yadav, ,CFD Analysis of a Rocket Nozzle with Two Inlets at Mach .1,vJournal ofEnvironmental Research and Development, Vol 5, No 2,2010, (pp 308-321).

[8]. P. Padmanathan, Dr. S. Vaidyanathan, Computational Analysis of Shockwave in Convergent Divergent Nozzle, International Journal of Engineering Research and Applications (IJERA), ISSN: 2248-9622, Vol. 2, Issue 2,Mar-Apr 2012, pp.1597-1605.

[9]. Natta, Pardhasaradhi.; Kumar, V.Ranjith.; Rao, Dr. Y.V. Hanumantha; Flow Analysis of Rocket Nozzle Using Computational Fluid Dynamics (Cfd), International Journal of Engineering Research and Applications (IJERA), ISSN: 2248-9622,Vol. 2, Issue 5, September- October 2012, pp.1226-1235.

[10]. Pandey,K.M.; Singh, A.P.; CFD Analysis of Conical Nozzle for Mach 3 at V arious Angles of Divergence with Fluent Software, International Journal of Chemical Engineering and Applications, Vol. 1, No. 2, August 2010, ISSN: 2010-0221. 